\title{
Multifunctional dendrimer/combretastatin
}

\section{A4 inclusion complexes enable in vitro targeted cancer therapy}

This article was published in the following Dove Press journal:

International Journal of Nanomedicine

13 October 201|

Number of times this article has been viewed

\section{Mengen Zhang ${ }^{1,2}$ \\ Rui Guo \\ Yin Wang ${ }^{2}$ \\ Xueyan $\mathrm{Cao}^{2}$ \\ Mingwu Shen ${ }^{2}$ \\ Xiangyang Shi ${ }^{1-3}$}

'State Key Laboratory for

Modification of Chemical Fibers and

Polymer Materials; ${ }^{2}$ College

of Chemistry, Chemical Engineering

and Biotechnology, Donghua

University, Shanghai, People's Republic

of China; ${ }^{3}$ Centro de Química da

Madeira, Universidade da Madeira,

Campus da Penteada, Funchal,

Portugal
Correspondence: Xiangyang Shi 2999 North Renmin Road, College of Chemistry, Chemical Engineering and Biotechnology, Donghua University, Shanghai 201620, People's Republic of China

Tel +862167792656

Fax +86 21 67792306804

Email xshi@dhu.edu.cn
Background: We report here a unique approach to using multifunctional dendrimer/ combretastatin A4 (CA4) inclusion complexes for targeted cancer therapeutics.

Methods: Amine-terminated generation 5 polyamidoamine dendrimers were first partially acetylated to neutralize a significant portion of the terminal amines, and then the remaining dendrimer terminal amines were sequentially modified with fluorescein isothiocyanate as an imaging agent and folic acid as a targeting ligand. The multifunctional dendrimers formed (G5.NHAc-FI-FA) were utilized to encapsulate the anticancer drug, CA4, for targeted delivery into cancer cells overexpressing folic acid receptors.

Results: The inclusion complexes of G5.NHAc-FI-FA/CA4 formed were stable and are able to significantly improve the water solubility of CA4 from 11.8 to $240 \mu \mathrm{g} / \mathrm{mL}$. In vitro release studies showed that the multifunctional dendrimers complexed with CA4 could be released in a sustained manner. Both 3-(4,5-dimethylthiazol-2-yl)-2,5-diphenyltetrazolium bromide colorimetric assay and morphological cell observation showed that the inhibitory effect of the G5.NHAc-FI-FA/CA4 complexes was similar to that of free CA4 at the same selected drug concentration. More importantly, the complexes were able to target selectively and display specific therapeutic efficacy to cancer cells overexpressing high-affinity folic acid receptors.

Conclusion: Multifunctional dendrimers may serve as a valuable carrier to form stable inclusion complexes with various hydrophobic anticancer drugs with improved water solubility, for targeting chemotherapy to different types of cancer.

Keywords: PAMAM dendrimers, combretastatin A4, inclusion complexes, targeted cancer therapy

\section{Introduction}

Combretastatin A4 (CA4) is a potent anticancer and antiangiogenesis substance isolated from the South African tree Combretum caffrum. It is an antimitotic agent that strongly inhibits the polymerization of tubulin by attaching to the colchicine-binding site of the $\beta$-tubulin subunit. ${ }^{1,2}$ CA4 can act as a vascular disrupting agent to elicit irreversible vascular shutdown within solid tumors and leave the normal vasculature intact because the endothelial cells in the immature vasculature of tumors are much more sensitive to the antimicrotubular effect of CA $4 .{ }^{3}$ In addition, CA4 also exhibits strong cytotoxicity against a broad spectrum of cancer cell lines, such as murine melanoma, human ovarian and colon cancer cells, and even those with multidrug resistance, ${ }^{4-6}$ which makes CA4 a potent cancer drug. However, the poor water solubility of CA4 in biological media and the resulting limited bioavailability significantly impair its antitumor activity for clinical applications. These limitations have led to the development of water-soluble 
structural analogs of CA4, eg, a phosphate CA4P prodrug. ${ }^{7,8}$ Nonetheless, this is not the optimum approach for the application of CA4 in chemotherapy, because the short half-life and wide distribution of the prodrug in vivo may reduce its therapeutic efficacy and cause undesirable side effects in normal tissues, such as cardiotoxicity and ataxia. ${ }^{9}$

To decrease the toxicity of CA4, it is necessary to develop a carrier system to improve the water solubility and bioavailability of the drug and maintain the tumor inhibition effect. Commonly used drug delivery systems include liposomes, ${ }^{10,11}$ polymeric nanoparticles, ${ }^{12-14}$ and peptide conjugates, ${ }^{15}$ which have been demonstrated to be able to load or conjugate CA4 to enhance its water solubility and improve its therapeutic efficacy. ${ }^{16-20}$ For instance, in a recent study, Ho et al used methoxyl poly(ethylene glycol)-poly(lactic acid) copolymers to conjugate paclitaxel, followed by encapsulation of CA4 to form self-assembled polymeric nanoparticles with both anticancer and antivasculature activity. ${ }^{19}$ In another study, Zhang et al synthesized Arg-Gly-Asp peptide-modified liposomes to coencapsulate CA4 as a vascular disrupting agent and doxorubicin as a cytotoxic agent to enhance the tumor inhibition response. ${ }^{10}$ Both in vitro and in vivo experiments confirmed an effective inhibitory effect on human umbilical vein endothelial cells and a significant therapeutic effect on malignant tumors. However, in most of these studies, only the antiangiogenesis property of CA4 is exploited, while its cytotoxicity and inhibitory effect on cancer cells has rarely been studied. Moreover, although the delivery system used to encapsulate hydrophobic CA4 may increase its aqueous solubility, the release rate of CA4 from these carriers has been relatively high, and about $80 \%$ of the loaded drug can be released within 24 hours, ${ }^{10}$ which might limit its therapeutic efficacy. Therefore, development of novel drug delivery systems for CA4 with a sustained-release profile remains a great challenge.

Polyamidoamine (PAMAM) dendrimers are a family of highly branched, monodispersed, synthetic macromolecules with a well defined structure and composition. ${ }^{21,22}$ Larger generation PAMAM dendrimers possess a uniform spherical shape with a suitable nanometer size, good water solubility, and biocompatibility after appropriate surface functionalization, making them an ideal carrier system for drug delivery. ${ }^{23,24}$ The internal hydrophobic cavities of dendrimers are able to encapsulate hydrophobic anticancer drugs, such as doxorubicin and 2-methoxyestradiol, and release the drug in a sustained manner. ${ }^{25-29}$ In the meantime, the abundant functional groups on the dendrimer surface can covalently link with imaging agents, targeting ligands, and therapeutic drugs for simultaneous imaging, targeting, and treatment of cancer cells. ${ }^{30-35}$ Therefore, for drug delivery applications, PAMAM dendrimers can be used either to encapsulate hydrophobic drugs physically within the dendrimer interior or as a platform to link drug molecules covalently on their surface.

In our previous work, ${ }^{26,27}$ we have shown that antitumor agents (eg, 2-methoxyestradiol and doxorubicin) are able to be effectively encapsulated within multifunctional folic acid-targeted generation 5 (G5) PAMAM dendrimers terminated with acetamide groups, and the stable inclusion complexes formed are able to be specifically delivered into cancer cells overexpressing folic acid receptors to exert the therapeutic inhibition effect of the anticancer drug via the receptor-mediated endocytosis pathway. It is anticipated that using a similar approach, CA4 can be physically loaded into the interiors of the folic acid-targeted G5 PAMAM dendrimers, allowing for targeted delivery of CA4 to cancer cells overexpressing the folic acid receptor.

In this present study, we utilized G5 PAMAM dendrimers modified with fluorescein isothiocyanate and folic acid and with acetyl terminal groups (G5.NHAc-FI-FA) to encapsulate the anticancer drug CA4. The encapsulation efficiency, release kinetics, and targeted inhibition of cancer cells overexpressing high affinity folic acid receptors were investigated in detail. To the best of our knowledge, this is the first report of a new formulation for the anticancer drug, CA4, using dendrimer-based nanotechnology. Another important feature of our study is that, unlike most of the other studies that have merely demonstrated the antiangiogenesis activity of a carrier system, the antitumor efficacy of CA4 can be readily demonstrated by the multifunctional dendrimer-mediated delivery pathway.

\section{Materials and methods}

Ethylenediamine core amine-terminated PAMAM dendrimers of generation $5\left(\mathrm{G} 5 . \mathrm{NH}_{2}\right)$, with a polydispersity index less than 1.08, were purchased from Dendritech (Midland, MI). 1-(3dimethylaminopropyl)-3-ethylcarbodiimide hydrochloride (EDC), CA4 (molecular structure shown in Scheme 1), and fluorescein isothiocyanate were supplied by J and K Chemical Ltd (Shanghai, China). Regenerated cellulose dialysis membranes (molecular weight cutoff 10,000) were acquired from Fisher Scientific (Hudson, NH). KB cells were obtained from the Institute of Biochemistry and Cell Biology, Chinese Academy of Sciences (Shanghai, China) and 3-[4,5-dimethyl2-thiazolyl]-2,5-diphenyl-2H-tetrazolium bromide (MTT) was purchased from Sigma-Aldrich. Unless otherwise specified, 


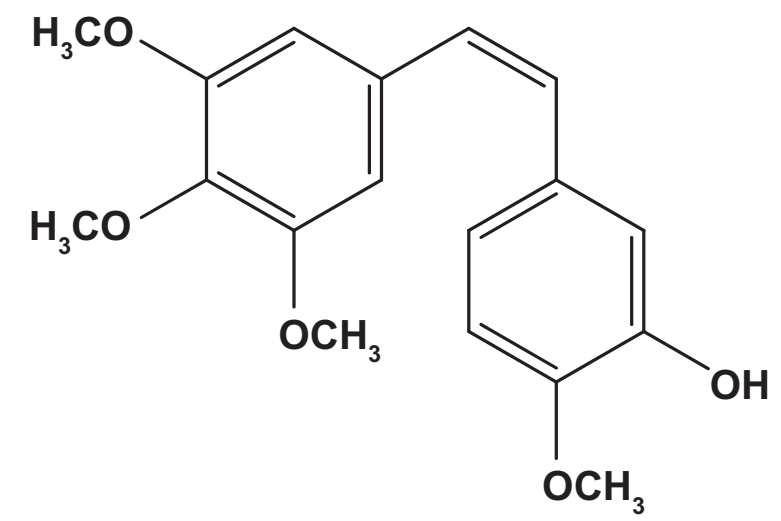

Scheme I Molecular structure of combretastatin A4

all cell culture media and reagents were purchased from Hangzhou Jinuo Biomedical Technology Co Ltd, China. The water used in all the experiments was purified using a Milli-Q Plus 185 water purification system (Millipore, Bedford, MA) with a resistivity higher than $18 \mathrm{~m} \Omega \mathrm{cm}$. Methanol and acetonitrile were of high-performance liquid chromatography (HPLC) grade. All other solvents and reagents were of analytical grade and used as received.

\section{Synthesis of G5.NHAc-FI-FA conjugates}

The terminal amines of G5. $\mathrm{NH}_{2}$ PAMAM dendrimers were partially converted to acetyl groups by reaction with acetic anhydride, and then the remaining dendrimer terminal amines were sequentially modified by fluorescein isothiocyanate and folic acid following a method described in our previous reports. ${ }^{36,37}$ Briefly, G5. $\mathrm{NH}_{2}$ dendrimers $(44.55 \mathrm{mg}$, $\left.1.713 \times 10^{-6} \mathrm{~mol}\right)$ were dissolved in dimethyl sulfoxide $(5 \mathrm{~mL})$ and mixed with triethylamine $\left(27.46 \mu \mathrm{L}, 1.541 \times 10^{-4} \mathrm{~mol}\right)$ under magnetic stirring for 30 minutes. Acetic anhydride $\left(12.95 \mu \mathrm{L}, 1.627 \times 10^{-4} \mathrm{~mol}\right)$ dissolved in $5 \mathrm{~mL}$ dimethyl sulfoxide was then added dropwise into the dendrimer/ triethylamine mixture solution under vigorous magnetic stirring at room temperature. The reaction was continued for 24 hours. The reaction mixture was then dialyzed through a 10,000 molecular weight cutoff membrane against phosphatebuffered saline (three times, $4 \mathrm{~L}$ ) and water (three times, $4 \mathrm{~L}$ ) for 3 days, followed by lyophilization to obtain the partially acetylated G5 dendrimers.

The partially acetylated G5 dendrimer obtained $(40.78 \mathrm{mg}$, $\left.1.41 \times 10^{-6} \mathrm{~mol}\right)$ was dissolved in dimethyl sulfoxide $(5 \mathrm{~mL})$ and reacted with fluorescein isothiocyanate $(3.11 \mathrm{mg}$, $7.05 \times 10^{-6} \mathrm{~mol}$ ) dissolved in $3 \mathrm{~mL}$ dimethyl sulfoxide at room temperature for 4 hours to obtain fluorescein isothiocyanatelabeled G5.NHAc-FI conjugates. EDC-activated folic acid was first prepared by mixing the dimethyl sulfoxide solutions of folic acid ( $\left.3.11 \mathrm{mg}, 7.05 \times 10^{-6} \mathrm{~mol}, 3 \mathrm{~mL}\right)$ and $\mathrm{EDC}(13.5 \mathrm{mg}$, $\left.7.05 \times 10^{-5} \mathrm{~mol}, 3 \mathrm{~mL}\right)$ at room temperature for 3 hours. The resulting solution of activated folic acid was added dropwise into the dimethyl sulfoxide solution of G5.NHAc-FI conjugates under vigorous magnetic stirring at room temperature for 2 days. Finally, the reaction mixture was dialyzed against phosphate-buffered saline buffer (three times, $4 \mathrm{~L}$ ) and water (three times, $4 \mathrm{~L}$ ) for 3 days, followed by lyophilization to obtain the G5.NHAc-FI-FA product.

\section{Formation of G5.NHAc-FI-FA/CA4 complexes}

The G5.NHAc-FI-FA dendrimer $\left(9.65 \mathrm{mg}, 2.853 \times 10^{-7} \mathrm{~mol}\right)$ was dissolved in $1.5 \mathrm{~mL}$ water. CA4 $\left(0.92 \mathrm{mg}, 2.853 \times 10^{-6} \mathrm{~mol}\right)$ with 10-fold molar equivalents of the dendrimer was dissolved in $300 \mu \mathrm{L}$ methanol and then mixed with the $1.5 \mathrm{~mL}$ dendrimer aqueous solution. This mixture was vigorously stirred overnight to evaporate the methanol solvent. The G5.NHAc-FI-FA/CA4 mixture was centrifuged (7000 rpm, 10 minutes) to remove precipitates related to non-complexed free CA4, which is almost insoluble in water. The precipitate collected was dissolved into $1 \mathrm{~mL}$ of methanol for HPLC analysis. The supernatant was lyophilized for 3 days to obtain the G5.NHAc-FI-FA/CA4 inclusion complex.

\section{Characterization techniques}

${ }^{1} \mathrm{H}$ NMR spectra of G5.NHAc-FI-FA conjugates were recorded on a Bruker AV400 nuclear magnetic resonance spectrometer. Samples were dissolved in $\mathrm{D}_{2} \mathrm{O}$ before NMR measurement. Ultraviolet-visible spectroscopy was performed using a Lambda 25 ultraviolet-visible spectrometer (Perkin Elmer, Boston, MA). Zeta potential measurements were carried out using a Zetasizer Nano ZS system (Malvern, Worcestershire, UK) equipped with a standard $633 \mathrm{~nm}$ laser. Dendrimer samples with a concentration of $1 \mathrm{mg} / \mathrm{mL}$ were measured under different $\mathrm{pH}$ conditions ( $\mathrm{pH}$ 5.0, $\mathrm{pH} 7.0$, and $\mathrm{pH}$ 10.0).

\section{In vitro release kinetics study}

To determine the release kinetics of CA4, free CA4 in ethanol or G5.NHAc-FI-FA/CA4 inclusion complex in water was placed in a dialysis bag with a molecular weight cutoff of 10,000 , hermetically tied, and suspended in $15 \mathrm{~mL}$ of aqueous phosphate buffer medium (20 mM, pH 7.4, pH 6.8, or $\mathrm{pH}$ 6.0). The entire system was kept in a vapor-bathing constant temperature vibrator at $37^{\circ} \mathrm{C}$. Three milliliters of the buffer medium were taken out at each predetermined time interval and measured by HPLC (see below). The volume of 
the outer phase buffer medium was maintained constant by replenishing $3 \mathrm{~mL}$ of the corresponding buffer solution.

\section{HPLC analysis}

An Agilent-1100 HPLC system was used for analysis of the CA4 drug concentration. A Jupiter C5 silica-based column $(250 \times 4.6 \mathrm{~mm}, 300 \mathrm{~A})$ was purchased from Phenomenex (Torrance, CA). Two Phenomenex Widepore C5 safety guards $(4 \times 3 \mathrm{~mm})$ were installed ahead of the Jupiter column. The mobile phase was a mixture solution containing $55 \%$ water with $0.05 \mathrm{M}$ sodium dihydrogen phosphate, $10 \%$ methanol, and $35 \%$ acetonitrile. The flow rate was set at $1 \mathrm{~mL} /$ minute and the injection volume was $35 \mu \mathrm{L}$. Detection of the eluted samples was performed at $294 \mathrm{~nm}$. The concentration of the noncomplexed or released CA4 was analyzed based on a free CA4 calibration curve, which showed a good linear relationship $(\mathrm{A}=35.82971 \mathrm{C}-10.69847, \mathrm{r}=0.9999)$ between the CA4 concentration $(\mathrm{C})$ and the peak area (A), with a linear range of 3.125-200 $\mu \mathrm{g} / \mathrm{mL}$.

\section{Cell biological evaluation}

KB cells (a human epithelial carcinoma cell line) were continuously grown in two $50 \mathrm{~mL}$ culture flasks, one in folic acid-free media and the other in regular RPMI 1640 medium supplemented with $10 \%$ heat-inactivated fetal bovine serum, $100 \mathrm{U} / \mathrm{mL}$ penicillin, $100 \mathrm{U} / \mathrm{mL}$ streptomycin, and $2.5 \mu \mathrm{M}$ of folic acid. The cells grown in folic acid-free media expressed high folic acid receptor levels (denoted as KB-HFAR), while the cells grown in folic acid-containing media expressed low folic acid receptor levels (denoted as KB-LFAR).

To determine if the G5.NHAc-FI-FA/CA4 complex was therapeutically active, one day before the experiments, the cells were plated into a 96 -well plate $\left(1 \times 10^{4}\right.$ cells per well $)$ in complete medium at $37^{\circ} \mathrm{C}$ and $5 \% \mathrm{CO}_{2}$. The next day, the medium was replaced with $200 \mu \mathrm{L}$ of folic acid-free medium consisting of phosphate-buffered saline $(10 \mu \mathrm{L})$, ethanol (1 $\mu \mathrm{L})$, G5.NHAc-FI-FA in phosphate-buffered saline solution $(10 \mu \mathrm{L}), \mathrm{CA} 4$ in ethanol solution $(1 \mu \mathrm{L})$, and G5.NHAc-FI-FA/ CA4 complex in phosphate-buffered saline $(10 \mu \mathrm{L})$. The final CA4 concentration in the drug-loaded and drug-free groups was $0.5 \mu \mathrm{M}$. The cells were then incubated for 48 hours at $37^{\circ} \mathrm{C}$ before MTT assay. After treatment with CA4 or dendrimer/ CA4 complexes for 48 hours, cell morphology was observed using a Leica DM IL LED inverted phase contrast microscope with a magnification of $200 \times$ for each sample.

To investigate the fate of the dendrimer/CA4 complexes, $1.0 \times 10^{5} \mathrm{~KB}$-HFAR cells were plated 24 hours before the experiment. The next day, cells were incubated with
G5.NHAc-FI-FA/CA4 complexes for one hour or 2 hours, and then with Lyso Tracker Red $50 \mathrm{nM}$ for a further hour. The cells were washed three times in rapid succession with phosphate-buffered saline and observed by confocal microscopy (Carl Zeiss LSM 700 laser scanning confocal microscope, Jena, Germany). Fluorescein isothiocyanate and Lyso Tracker Red fluorescence was excited at $488 \mathrm{~nm}$ and $568 \mathrm{~nm}$, respectively. Samples were imaged using a $63 \times$ oil-immersion objective lens.

In order to confirm targeted inhibition of KB-HFAR cells, the G5.NHAc-FI-FA/CA4 complex with the same CA4 concentration $(0.5 \mu \mathrm{M})$ was added to both KB-HFAR and KBLFAR cells. The medium in the wells containing dendrimer/ CA4 complexes was completely removed and replenished with the same volume of fresh medium without the dendrimer/ CA4 complexes after 3 hours of incubation. The control comprised KB-HFAR cells treated with the same volume of phosphate-buffered saline. The cells were then incubated for 48 hours at $37^{\circ} \mathrm{C}$ before MTT assay. Parallel cell samples after 3 hours of incubation of G5.NHAc-FI-FA/CA4 complex and subsequent change with fresh medium without the dendrimer/ CA4 complexes was observed by confocal microscopy to check the binding specificity of the G5.NHAc-FI-FA/CA4 complex for KB cells. Fluorescein isothiocyanate fluorescence was excited with a $488 \mathrm{~nm}$ argon blue laser. The optical section thickness was set at $5 \mu \mathrm{m}$. Samples were imaged using a $63 \times$ oil-immersion objective lens.

An MTT assay was used to quantify viability of the cells. To determine the therapeutic efficacy of the dendrimer/CA4 complex, metabolically active cells were detected by adding MTT to each well after 48 hours of incubation with CA4 or dendrimer/CA4 complex. For the targeted cancer cell inhibition study, MTT assay was performed after the cells were treated with dendrimer/CA4 complexes for 3 hours, followed by changing the medium to fresh drug-free medium and culturing the cells for 48 hours. The plates were read at $570 \mathrm{~nm}$. The means and standard deviation for the triplicate wells were reported.

\section{Statistical analysis}

One-way analysis of variance was used to evaluate the statistical significance of the therapeutic efficacy of the CA4 drug. A $P$ value of $<0.05$ was considered to be statistically significant.

\section{Results and discussion Synthesis and characterization of G5.NHAc-FI-FA dendrimers}

Because of its small size (diameter $5.4 \mathrm{~nm}$ ) comparable with hemoglobin, ${ }^{38}$ an amine-terminated G5 PAMAM dendrimer 
was selected to conjugate with fluorescein isothiocyanate as the imaging agent and folic acid as the targeting ligand. The relative small size of the dendrimers enables them to be cleared easily from the blood via the kidneys, ${ }^{39}$ obviating the need for biodegradability. G5. $\mathrm{NH}_{2}$ dendrimers have plenty of terminal amine groups at their periphery (theoretically 128 primary amine groups), enabling tunable modification with different functionalities. In this work, the multifunctional conjugate, G5.NHAc-FI-FA, was synthesized in three steps. First, 95 amine groups on the G5 dendrimer surface were acetylated to minimize nonspecific binding of the dendrimers to cell membranes and to improve the biocompatibility of the dendrimer species. Second, fluorescein isothiocyanate moieties were conjugated to the partially acetylated dendrimer by thiourea bonds in order to detect the intracellular uptake of the dendrimer carrier. Based on previous studies, ${ }^{27,40,41}$ linking only five fluorescein isothiocyanate moieties onto each partially acetylated G5 dendrimer is sufficient for fluorescent detection. Third, 5 molar-equivalent folic acid molecules were conjugated to each G5.NHAc-FI dendrimer by amide bonds between the $\gamma$-carboxyl group of folic acid and the remaining primary amino group of the dendrimer, which is known to be sufficient to target cancer cells overexpressing high-affinity folic acid receptors efficiently. ${ }^{42}$

The chemical structure of the G5.NHAc-FI-FA conjugate was characterized by ${ }^{1} \mathrm{H}$ NMR (Figure 1). The emergence of a peak at $1.87 \mathrm{ppm}$ is related to the $-\mathrm{CH}_{3}$ protons of the acetyl groups, and the peaks in aromatic proton region are assigned to the characteristic proton peaks from fluorescein isothiocyanate (peaks a, b, and c) and folic acid (peaks d, e, and f), in agreement with previous data reported in the literature. ${ }^{27}$ Based on NMR integration, the average number of acetyl groups, fluorescein isothiocyanate, and folic acid coupled to each dendrimer was estimated to be $94.0,4.5$, and 5.0, respectively, which is close to the initial molar feeding ratio.

The G5.NHAc-FI-FA conjugate formed was further characterized using ultraviolet-visible spectroscopy (Figure 2). The pristine $\mathrm{G} 5 . \mathrm{NH}_{2}$ dendrimer only shows ultraviolet absorbance at a wavelength below $250 \mathrm{~nm}$, which is typical of the aliphatic<smiles>O=C1OC(c2ccc(NC(=S)NS)cc2)(c2ccc(O)cc2Oc2cc(O)ccc2F)c2ccccc21</smiles><smiles></smiles>

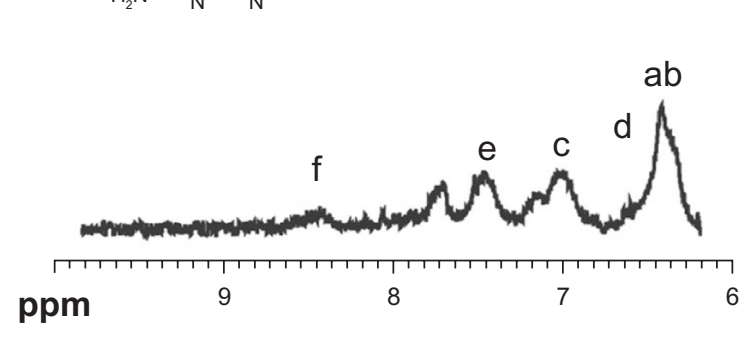

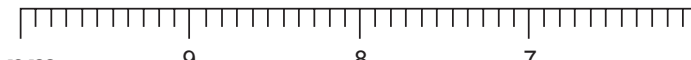
ppm 9 8

Figure I 'H NMR spectrum of G5.NHAc-FI-FA dendrimers.

Abbreviation: G5.NHAc-FI-FA, fluorescein isothiocyanate-modified and folic acid-modified G5 PAMAM dendrimers with acetyl terminal groups. 


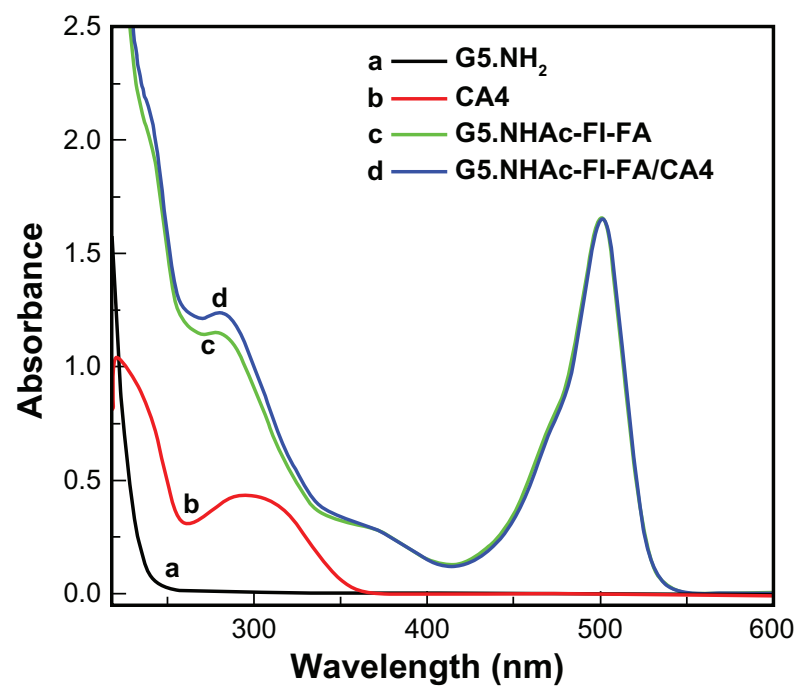

Figure 2 Ultraviolet-visible spectra of $\mathrm{CA} 4$ in ethanol, $\mathrm{G} 5 . \mathrm{NH}_{2}$ dendrimers, G5.NHAc-FI-FA dendrimers, and G5.NHAc-FI-FA/CA4 complexes in aqueous solution.

Abbreviations: G5, generation 5; G5.NHAc-FI-FA, fluorescein isothiocyanatemodified and folic acid-modified G5 PAMAM dendrimers with acetyl terminal groups; CA4, combretastatin A4.

structure of dendrimers. After modification with both fluorescein isothiocyanate and folic acid, two obvious absorption peaks at $280 \mathrm{~nm}$ and $500 \mathrm{~nm}$ appeared in the spectrum of the G5.NHAc-FI-FA conjugates, which are assigned to the characteristic absorption peak of folic acid and fluorescein isothiocyanate, respectively. Both ${ }^{1} \mathrm{H}$ NMR and ultravioletvisible spectroscopy indicate the successful attachment of fluorescein isothiocyanate and folic acid moieties onto the dendrimer surface, in agreement with our previous study. ${ }^{27}$

\section{Formation of G5.NHAc-FI-FA/ CA4 inclusion complexes}

The poor water solubility of the antitumor drug CA4 facilitates its effective encapsulation within the relatively hydrophobic interior of the dendrimers. The dendrimer/CA4 complexes in this new formulation are expected to have improved water solubility and thus enhanced bioavailability. The G5.NHAc-FI-FA/ CA4 complexes were characterized by ultraviolet-visible spectroscopy (Figure 2). It is clear that free CA4 dissolved in ethanol has a typical absorption peak at $294 \mathrm{~nm}$. After encapsulation within the G5.NHAc-FI-FA dendrimers, the G5.NHAc-FI-FA/ CA4 complexes had an absorption enhancement at $294 \mathrm{~nm}$, when compared with that of the G5.NHAc-FI-FA dendrimers without CA4 encapsulation. This demonstrates effective encapsulation of CA4 within the dendrimer conjugate. The concentration of CA4 loaded into the multifunctional dendrimer conjugate was determined to be $240 \mu \mathrm{g} / \mathrm{mL}$ by HPLC, which represents at least a 20 -fold increase in the aqueous solubility of CA4 $(11.8 \mu \mathrm{g} / \mathrm{mL}) .{ }^{12}$ Therefore, the application of G5.NHAc-FI-FA to load hydrophobic drug CA4 can significantly improve its aqueous solubility. From our calculations, we show that about 4.8 CA4 molecules are encapsulated within each multifunctional dendrimer.

The stability of the G5.NHAc-FI-FA/CA4 complexes formed under different conditions is of paramount importance for their biological applications. We showed that the lyophilized powder of the G5.NHAc-FI-FA/CA4 inclusion complexes could be completely dissolved in aqueous solution under different $\mathrm{pH}$ conditions $(\mathrm{pH}$ 5.0, 7.0, and 10.0, respectively), similar to the G5.NHAc-FI-FA dendrimers without CA4 (Figure S1). This suggests that the G5.NHAcFI-FA/CA4 complexes have similar colloidal stability to that of the G5.NHAc-FI-FA dendrimers without the drug complexed under the selected $\mathrm{pH}$ conditions. The zeta potentials of the G5.NHAc-FI-FA conjugates and G5.NHAcFI-FA/CA4 complexes under different $\mathrm{pH}$ conditions were measured and are listed in Table 1. The surface potentials of the G5.NHAc-FI-FA dendrimers before and after drug loading had approximately similar values, indicating that encapsulation of CA4 does not appreciably affect the surface charge properties of the dendrimers. The larger values at pH 5.0 for both dendrimers and complexes compared with those at $\mathrm{pH} 7.0$ can be ascribed to protonation of the tertiary amines in the dendrimer. ${ }^{43}$ The change in surface potential of both the dendrimers and complexes with $\mathrm{pH}$ followed the same trend as that of the G5.NHAc dendrimers described in our previous work. ${ }^{25}$ In addition, the G5.NHAc-FI-FA/ $\mathrm{CA} 4$ complexes in aqueous solution (eg, water, phosphatebuffered saline buffer with a $\mathrm{pH}$ value of 7.4, and cell culture medium) stored at $4^{\circ} \mathrm{C}$ were stable for at least 12 months (Figure S2), which is again essential for their further biological applications.

\section{In vitro release kinetics of G5.NHAc- FI-FA/CA4 complexes}

To evaluate the in vitro release kinetics of CA4 from the G5.NHAc-FI-FA/CA4 complexes under physiological

Table I Zeta potential values of G5.NHAc-FI-FA dendrimers and G5.NHAc-FI-FA/CA4 complexes under different $\mathrm{pH}$ conditions

\begin{tabular}{llll}
\hline Materials & \multicolumn{3}{l}{ Zeta potential $(\mathbf{m V})$} \\
\cline { 2 - 4 } & pH 5.0 & pH 7.0 & pH 10.0 \\
\hline G5.NHAc-FI-FA dendrimer & $14.8 \pm 7.3$ & $9.7 \pm 5.9$ & $-11.2 \pm 5.0$ \\
G5.NHAc-FI-FA/CA4 complex & $13.5 \pm 10.1$ & $7.2 \pm 3.9$ & $-17.3 \pm 9.2$ \\
\hline
\end{tabular}

Abbreviations: G5.NHAc-FI-FA, fluorescein isothiocyanate-modified and folic acid-modified G5 PAMAM dendrimers with acetyl terminal groups; CA4, combretastatin A4. 
conditions, three kinds of phosphate buffer $(20 \mathrm{mM})$ with different $\mathrm{pHs}(\mathrm{pH} 7.4, \mathrm{pH} 6.8$, and $\mathrm{pH}$ 6.0) were selected as release media. $\mathrm{pH} 7.4$ is the physiological $\mathrm{pH}, \mathrm{pH} 6.8$ corresponds to the slight acidic environment of tumor tissue in vivo, and pH 6.0 is the endosomal pH. Figure 3 shows the release profiles of free CA 4 and CA4 from the complexes at $37^{\circ} \mathrm{C}$. It can be seen that within 2 hours about $21 \%$ (pH 7.4), 26\% (pH 6.8), and 28\% (pH 6.0) of loaded CA4 is released from the complexes, while more than $95 \%$ of free CA4 in ethanol is released at $\mathrm{pH}$ 7.4. With inclusion in G5.NHAc-FI-FA dendrimers, only about 28\% ( $\mathrm{pH} 7.4$ ), $32 \%$ (pH 6.8), and 33\% (pH 6.0) of CA4 is released from the complexes, even after 24 hours. This suggests that the relatively hydrophobic interior of the G5.NHAc-FI-FA conjugates can effectively retain hydrophobic CA4 molecules within the dendrimer interior and maintain a slow but constant release rate. It is worthwhile to note that the release rates of $\mathrm{CA} 4$ from the complexes at $\mathrm{pH} 6.8$ and $\mathrm{pH}$ 6.0 are more or less similar, but both are slightly higher than that at $\mathrm{pH} 7.4$, probably because lower $\mathrm{pH}$ can render the dendrimer interior less hydrophobic due to a higher level of protonation of the internal dendrimer tertiary amines. Therefore, it can be expected that the designed system is able to prolong the release time of $\mathrm{CA} 4$, to release anticancer drug in the endosomal environment, and also to have a slightly faster release rate in weakly acidic tumor tissue than in normal tissue.

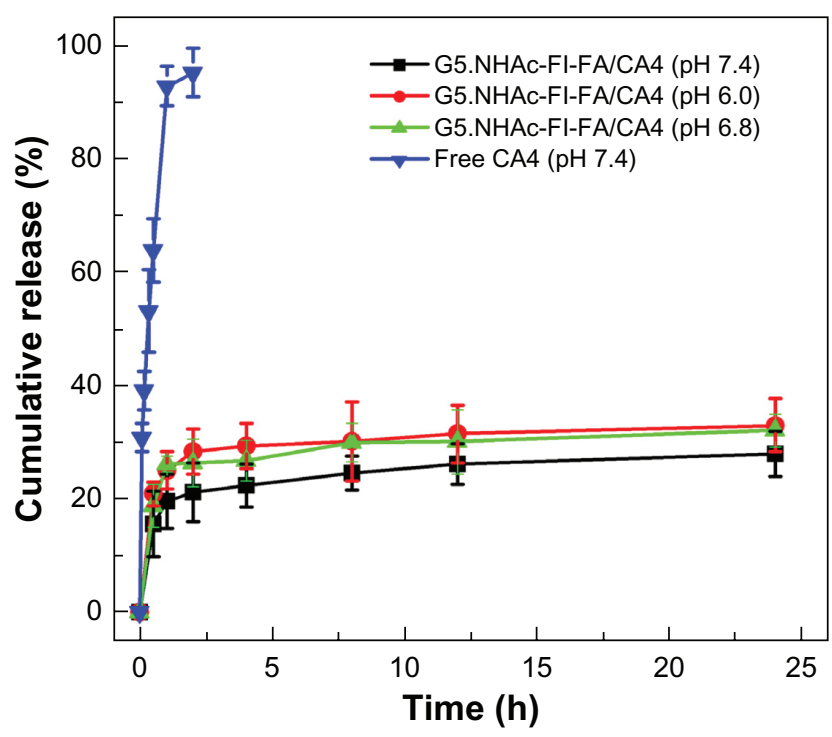

Figure 3 In vitro release profiles of CA4 from G5.NHAc-FI-FA/CA4 complexes in phosphate buffer $(\mathrm{pH} 7.4, \mathrm{pH} 6.8$, and $\mathrm{pH}$ 6.0) and from free CA4 dissolved in ethanol solution in phosphate buffer $\left(\mathrm{pH} \mathrm{7.4)}\right.$ at $37^{\circ} \mathrm{C}$.

Abbreviations: G5.NHAc-FI-FA, fluorescein isothiocyanate-modified and folic acid-modified G5 PAMAM dendrimers with acetyl terminal groups; CA4, combretastatin A4.

\section{In vitro therapeutic efficacy of G5.NHAc-FI-FA/CA4 complexes}

To determine if the encapsulated CA4 is pharmacologically active, in vitro cytotoxicity tests of the G5.NHAc-FI-FA/ CA4 complexes against $\mathrm{KB}$ cells were performed using a standard MTT colorimetric assay. To determine the dose of CA4 complexed with G5.NHAc-FI-FA dendrimers for targeted cancer cell therapy and for comparison with the free drug, we tested the dose-dependent cytotoxicity of free CA4 and G5.NHAc-FI-FA/CA4 complexes (Figure S3). We showed that the free drug at a concentration as low as $50 \mathrm{nM}$ could have significant cytotoxicity in $\mathrm{KB}$ cells, whereas the G5.NHAc-FI-FA/CA4 complexes started to show the therapeutic activity of CA4 at around $0.5 \mu \mathrm{M}$. This would be due to the limited release of the drug from the complexes, resulting in lower bioavailability of the drug. Therefore, in our subsequent studies, we chose a CA4 concentration of $0.5 \mu \mathrm{M}$ to demonstrate the therapeutic efficacy of CA4 under different conditions. Figure 4 shows the viability of KB cells treated with phosphate-buffered saline $(10 \mu \mathrm{L})$, ethanol $(1 \mu \mathrm{L}), \mathrm{CA} 4$ in ethanol solution $(1 \mu \mathrm{L}), \mathrm{G} 5$.NHAc-FI-FA in phosphate-buffered saline $(10 \mu \mathrm{L})$, and G5.NHAc-FI-FA/ CA4 in phosphate-buffered saline $(10 \mu \mathrm{L})$, respectively, for 48 hours at $37^{\circ} \mathrm{C}$. Ethanol $(1 \mu \mathrm{L})$ and phosphate-buffered saline $(10 \mu \mathrm{L})$ were used as solvents to dissolve the free CA4, the G5.NHAc-FI-FA dendrimer, and the G5.NHAcFI-FA/CA4 complexes, respectively. G5.NHAc-FI-FA

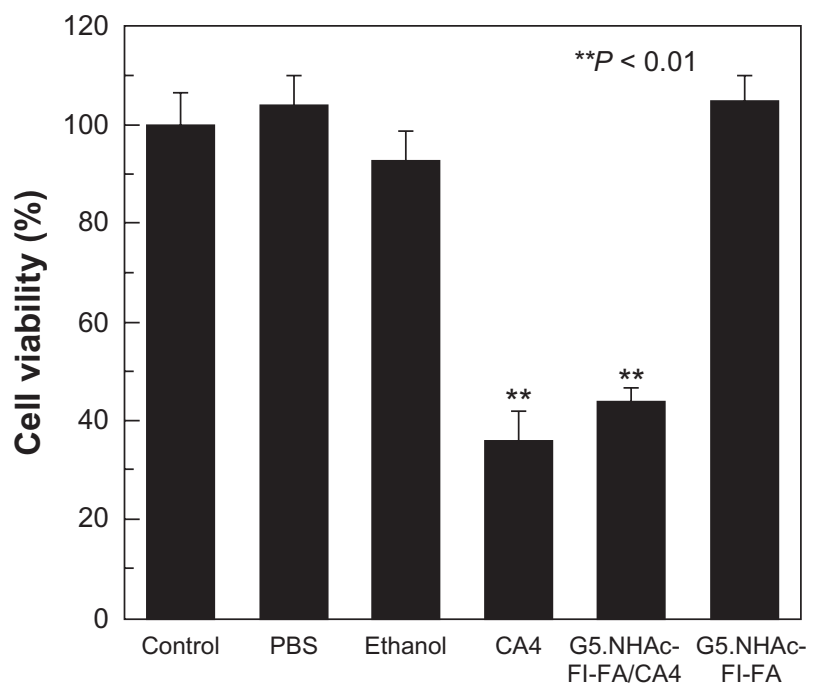

Figure 4 Viability of KB cells after treatment with $10 \mu \mathrm{L}$ phosphate-buffered saline, I $\mu \mathrm{L}$ ethanol, free CA4 $(0.5 \mu \mathrm{M})$ in I $\mu \mathrm{L}$ ethanol, G5.NHAc-FI-FA/CA4 complexes with a CA4 concentration of $0.5 \mu \mathrm{M}$, and G5.NHAc-FI-FA.

Note: The data are expressed as the mean \pm standard deviation.

Abbreviations: G5.NHAc-FI-FA, fluorescein isothiocyanate-modified and folic acidmodified G5 PAMAM dendrimers with acetyl terminal groups; CA4, combretastatin A4; G5, generation 5 . 
dendrimer with a concentration similar to that used for the preparation of dendrimer/drug complex was also tested. The results showed that the G5.NHAc-FI-FA/CA4 complexes had cytotoxic activity similar to that of free CA4 at a similar drug concentration of $0.5 \mu \mathrm{M}$, whereas added amounts of ethanol, phosphate-buffered saline, and G5.NHAc-FI-FA dendrimer in phosphate-buffered saline were found to have no cytotoxicity when compared with the untreated control group. Therefore, the G5.NHAc-FI-FA carrier is biocompatible at the given concentration, and the antitumor effect of G5.NHAc-FI-FA/CA4 complexes is related solely to the loaded CA4 drug.

The therapeutic activity of the G5.NHAc-FI-FA/CA4 complexes was further confirmed by visual observation of the morphology of KB cells after treatment (Figure 5). The morphology of KB cells treated with $1 \mu \mathrm{L}$ ethanol (Figure 5B), $10 \mu \mathrm{L}$ phosphate-buffered saline (Figure 5D), and $10 \mu \mathrm{L}$ G5.NHAc-FI-FA dendrimer in phosphate-buffered saline (Figure 5E) is similar to that of the control group (Figure 5A), indicating that the added ethanol, phosphate-buffered saline, and G5.NHAc-FI-FA dendrimer at a concentration similar to that used to encapsulate CA4 $(0.5 \mu \mathrm{M})$ are nontoxic. In contrast, a significant proportion of $\mathrm{KB}$ cells treated with the G5.NHAc-FI-FA/CA4 complexes (Figure 5F) or free CA4 in ethanol solution (Figure 5C) with a similar drug concentration $(0.5 \mu \mathrm{M})$ became detached from the bottom of the plate and were rounded in shape, indicative of cells that have undergone apoptosis. These results are consistent with the MTT assay data.

\section{Targeted antitumor efficacy of G5.NHAc-FI-FA/CA4 complexes}

We next explored the targeted antitumor efficacy of the G5.NHAc-FI-FA/CA4 complexes. The folic acid receptor is known to be overexpressed in many types of cancer cells, including in the ovary, kidney, uterus, testis, brain, colon, lung, and myelocytic leukemia, whereas its expression in normal tissues and organs is quite limited. ${ }^{44}$ Therefore, in this study, folic acid was covalently linked to the surface of the dendrimer for targeted delivery of the CA4 drug to tumor cells overexpressing high-affinity folic acid receptors via the receptor-mediated endocytosis pathway. KB cells with both low levels and high levels of folic acid receptors were cultured in order to test the targeted antitumor efficacy of the CA4 drug encapsulated within the multifunctional G5.NHAcFI-FA dendrimers. The difference between KB-HFAR and KB-LFAR cells in terms of their surface expression of folic acid receptors has been quantified and demonstrated in our previous work by flow cytometry, confocal microscopy, and other imaging techniques. ${ }^{40,41}$

Prior to exploring the targeted antitumor efficacy of the G5.NHAc-FI-FA/CA4 complexes, it was necessary to confirm the targeting specificity of the complexes to folic acid receptor-overexpressing KB cells. The fluorescein isothiocyanate moieties linked onto the G5 dendrimers enabled confocal microscopic imaging of cellular uptake and internalization of the G5.NHAc-FI-FA/CA4 complexes. Figure 6 shows the confocal microscopic images of the KBHFAR cells and KB-LFAR cells after 3 hours of incubation
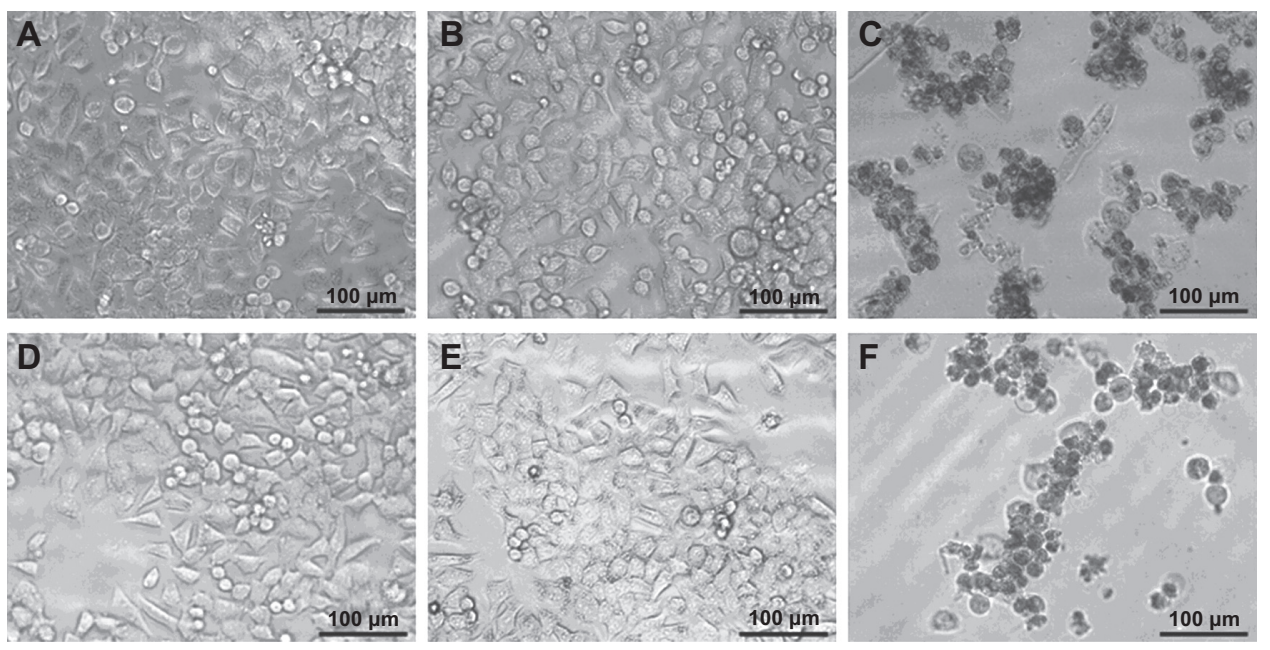

Figure 5 Phase contrast microscopic images of $(\mathbf{A}) \mathrm{KB}$ cells without treatment and KB cells treated with (B) I $\mu \mathrm{L}$ ethanol, (C) free CA4 in I $\mu \mathrm{L}$ ethanol (0.5 $\mu \mathrm{M})$, (D) I0 $\mu \mathrm{L}$ phosphate-buffered saline buffer, (E) G5.NHAc-FI-FA dendrimers in $10 \mu \mathrm{L}$ phosphate-buffered saline, and (F) G5.NHAc-FI-FA/CA4 complexes with a CA4 concentration of $0.5 \mu \mathrm{M}$ in $10 \mu \mathrm{L}$ phosphate-buffered saline, respectively.

Abbreviations: G5, generation 5; G5.NHAc-FI-FA, fluorescein isothiocyanate-modified and folic acid-modified G5 PAMAM dendrimers with acetyl terminal groups; CA4, combretastatin A4. 

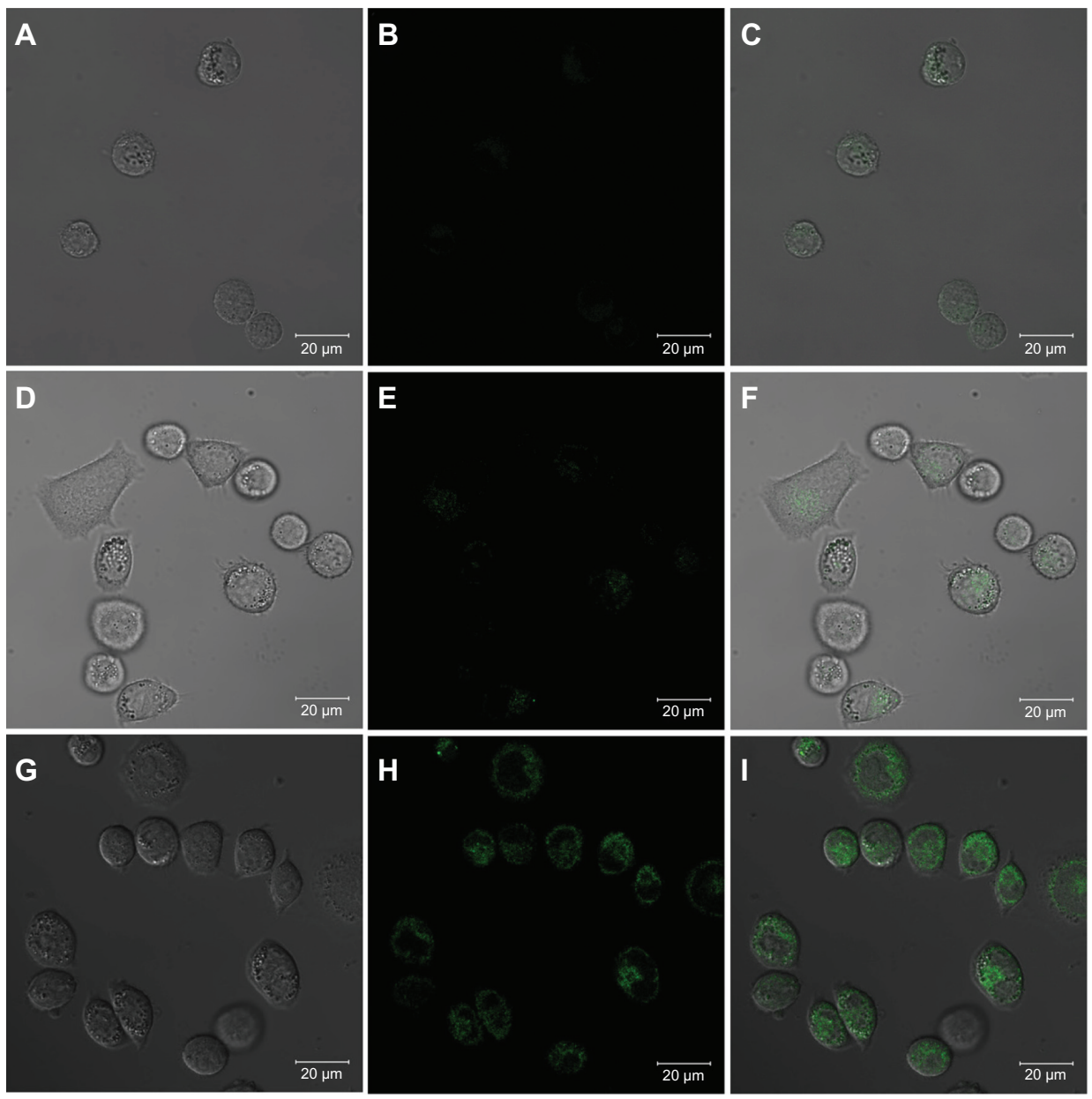

Figure 6 Confocal microscopic images of KB-HFAR cells incubated with phosphate-buffered saline buffer (A, B, and C), KB-LFAR cells (D, E, and F), and KB-HFAR cells (G, H, and I) treated with G5.NHAc-FI-FA/CA4 complexes. Differential interference contrast images (left panels), fluorescent images (middle panels), and merged images with the above two modes (right panels) were collected under similar instrumental conditions.

Abbreviations: G5, generation 5; G5.NHAc-FI-FA, fluorescein isothiocyanate-modified and folic acid-modified G5 PAMAM dendrimers with acetyl terminal groups; CA4, combretastatin A4; HFAR, high folic acid receptor levels; LFAR, low folic acid receptor levels.

with G5.NHAc-FI-FA/CA4 complexes. It is clear that only KB-HFAR cells displayed significant fluorescence signals, which were associated with specific internalization of the G5.NHAc-FI-FA/CA4 complexes into the cytoplasm of the cells (Figure 6G-I). In contrast, under similar microscopic conditions, KB-LFAR cells treated with the same complexes did not show detectable green fluorescence signals in the confocal microscopic images (Figure 6D-F), which is similar to the KB-HFAR cells treated with phosphate-buffered saline (Figure 6A-C). This result suggests that complexation of CA4 within the G5.NHAc-FI-FA dendrimers does not compromise the targeting specificity of the folic acid-modified dendrimers, in agreement with our previous results. ${ }^{27}$

To explore further the fate of the G5.NHAc-FI-FA/CA4 complexes after internalization into KB-HFAR cells, the lysosomal compartment of the cells was stained with Lyso Tracker Red probes after treatment with G5.NHAc-FI-FA/CA4 complexes for one hour or 2 hours. It was clear that a significant portion of the complexes (labeled with fluorescein isothiocyanate, green) merged with the red color, which is the location of the lysosomes in KB-HFAR cells, indicating that the complexes are able to enter into the lysosomes of cells (Figure S4). In contrast, the control cells did not show any fluorescence signals (Figure S4A). The complexes may be able to escape the lysosomes, but it is hard to make a definitive statement in this regard based on confocal microscopic observation alone.

Targeted inhibition of folic acid receptor-overexpressing KB cells using the G5.NHAc-FI-FA/CA4 complexes was confirmed by MTT assay. After incubation of the cells with the complexes for 3 hours, the medium in the wells was replaced with the same volume of fresh medium not containing dendrimer/CA4 complexes. The cells were then incubated for 48 hours at $37^{\circ} \mathrm{C}$, and an MTT assay was performed to detect cell viability. Figure 7 shows the viability of untreated 


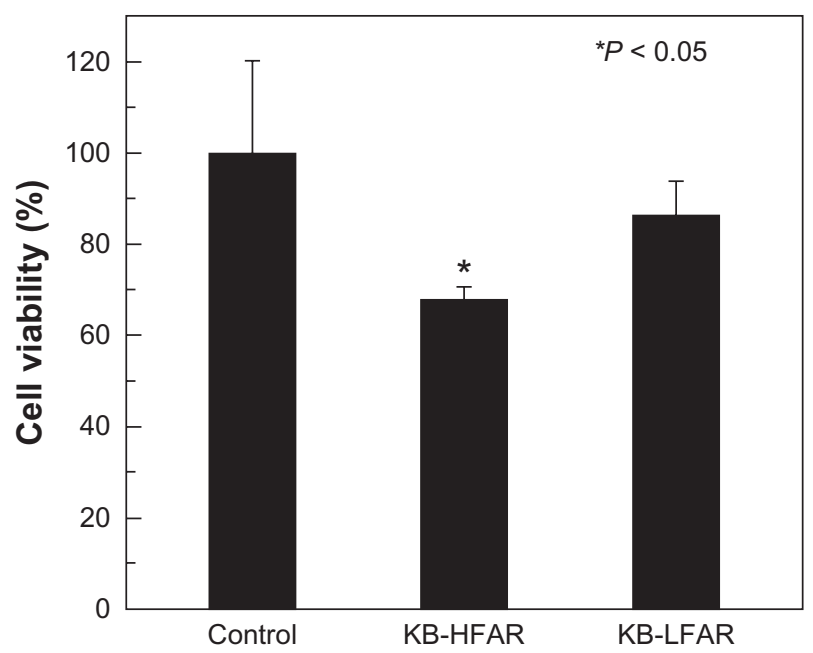

Figure 7 The viability of KB-HFAR and KB-LFAR cells after treatment with G5.NHAc-FI-FA/CA4 complexes. The KB-HFAR cells without treatment were used as a control group.

Abbreviations: G5, generation 5; G5.NHAc-FI-FA, fluorescein isothiocyanatemodified and folic acid-modified G5 PAMAM dendrimers with acetyl terminal groups; CA4, combretastatin A4; HFAR, high folic acid receptor levels; LFAR, low folic acid receptor levels.

KB-HFAR cells (control) and KB-HFAR and KB-LFAR cells treated with the G5.NHAc-FI-FA/CA4 complexes. It can be clearly seen that treatment of KB-HFAR cells with the G5.NHAc-FI-FA/CA4 complexes results in a significant decrease (of about $32 \%$ ) in cell viability $(P<0.05$ versus control). In contrast, approximately $86 \%$ of KB-LFAR cells were still alive after the same treatment $(P>0.05$ versus control), suggesting a weaker therapeutic effect of CA4 complexed with G5.NHAc-FI-FA dendrimers in KB-LFAR cells. It should be noted that there was no difference in viability between KB-HFAR and KB-LFAR cells before treatment with the dendrimer/CA4 complexes. These results indicate that the G5.NHAc-FI-FA/CA4 complexes enable targeted inhibition of cancer cells via receptor-mediated binding and intracellular uptake.

\section{Conclusion}

In summary, multifunctional G5 dendrimers modified with fluorescein isothiocyanate and folic acid were synthesized to encapsulate an anticancer drug, CA4. The inclusion complexes of G5.NHAc-FI-FA/CA4 formed were able to improve the water solubility of the hydrophobic CA4 significantly and enabled release of the drug in a sustained manner, with a slow release rate. More importantly, the G5.NHAc-FI-FA/CA4 complexes not only displayed an inhibitory effect on cancer cells similar to that of free CA4, but also delivered CA4 specifically to cancer cells with a high level of folic acid receptor expression and exerted a targeted therapeutic effect.
The significance of our study is that using dendrimer-based nanotechnology, a new CA4 drug formulation could be developed with the capability to target and kill cancer cells specifically via a receptor-mediated endocytosis pathway. To demonstrate further the efficacy of these multifunctional dendrimer/CA4 complexes, we will be performing in vivo studies in the future. With a unique capacity to encapsulate hydrophobic cancer drugs and to endow drugs with targeting specificity, these multifunctional dendrimers may act as a valuable carrier for a range of hydrophobic anticancer drugs for targeted chemotherapy.

\section{Acknowledgment}

Rui Guo and Mengen Zhang equally contributed to this work. This research was funded by the National Natural Science Foundation of China (20974019 and 81101150), the Program for Professor of Special Appointment (Eastern Scholar) at Shanghai Institutions of Higher Learning, the Scientific Research Foundation for the Returned Overseas Chinese Scholars, State Education Ministry, and the Fundamental Research Funds for the Central Universities (for RG, MS, and XS). RG thanks the Shanghai Natural Science Foundation (10ZR1400800). XS gratefully acknowledges the Fundação para a Ciência e a Tecnologia and the Santander Bank for supporting a Chair in Nanotechnology.

\section{Disclosure}

The authors report no conflicts of interest relevant to this research.

\section{References}

1. Tozer GM, Kanthou C, Parkins CS, Hill SA. The biology of the combretastatins as tumour vascular targeting agents. Int J Exp Pathol. 2002;83(1):21-38.

2. West CM, Price P. Combretastatin A4 phosphate. Anticancer Drugs. 2004;15(3):179-187.

3. Griggs J, Hesketh R, Smith GA, et al. Combretastatin-A4 disrupts neovascular development in non-neoplastic tissue. Br J Cancer. 2001; 84(6):832-835.

4. Nabha SM, Wall NR, Mohammad RM, Pettit GR, Al-Katib AM. Effects of combretastatin A-4 prodrug against a panel of malignant human B-lymphoid cell lines. Anticancer Drugs. 2000;11(5):385-392.

5. El-Zayat A, Degen D, Drabek S, Clark GM, Pettit GR, Von Hoff DD. In vitro evaluation of the antineoplastic activity of combretastatin A-4, a natural product from Combretum caffrum (arid shrub). Anticancer Drugs. 1993;4(1):19-25.

6. Lawrence NJ, Rennison D, Woo M, McGown AT, Hadfield JA. Antimitotic and cell growth inhibitory properties of combretastatin A-4-like ethers. Bioorg Med Chem Lett. 2001;11(1):51-54.

7. Dorr RT, Dvorakova K, Snead K, Alberts DS, Salmon SE, Pettit GR. Antitumor activity of combretastatin-A4 phosphate, a natural product tubulin inhibitor. Invest New Drugs. 1996;14(2):131-137.

8. Rustin GJ, Galbraith SM, Anderson H, et al. Phase I clinical trial of weekly combretastatin A4 phosphate: Clinical and pharmacokinetic results. Int J Clin Oncol. 2003;21(15):2815-2822. 
9. Young SL, Chaplin DJ. Combretastatin A4 phosphate: background and current clinical status. Expert Opin Investig Drugs. 2004; 13(9):1171-1182.

10. Zhang YF, Wang JC, Bian DY, Zhang X, Zhang Q. Targeted delivery of RGD-modified liposomes encapsulating both combretastatin A-4 and doxorubicin for tumor therapy: In vitro and in vivo studies. Eur $J$ Pharm Biopharm. 2010;74(3):467-473.

11. Nallamothu R, Wood GC, Pattillo CB, et al. A tumor vasculature targeted liposome delivery system for combretastatin A4: Design, characterization, and in vitro evaluation. AAPS Pharm Sci Tech. 2006;7(2): E1-E10.

12. Wang Y, Yang T, Wang X, Wang J, Zhang X, Zhang Q. Targeted polymeric micelle system for delivery of combretastatin A4 to tumor vasculature in vitro. Pharm Res. 2010;27(9):1861-1868.

13. Wang YG, Yang TY, Wang X, et al. Materializing sequential killing of tumor vasculature and tumor cells via targeted polymeric micelle system. J Control Release. 2011;149(3):299-306.

14. Wang Z, Chui WK, Ho PC. Nanoparticulate delivery system targeted to tumor neovasculature for combined anticancer and antiangiogenesis therapy. Pharm Res. 2011;28(3):585-596.

15. Falciani C, Brunetti J, Pagliuca C, et al. Design and in vitro evaluation of branched peptide conjugates: turning nonspecific cytotoxic drugs into tumor-selective agents. Chem Med Chem. 2010;5(4):567-574.

16. Sengupta S, Eavarone D, Capila I, et al. Temporal targeting of tumour cells and neovasculature with a nanoscale delivery system. Nature. 2005;436(7050):568-572.

17. Pattillo CB, Venegas B, Donelson FJ, et al. Radiation-guided targeting of combretastatin encapsulated immunoliposomes to mammary tumors. Pharm Res. 2009;26(5):1093-1100.

18. Ma L, Liu YL, Ma ZZ, et al. Targeted treatment of choroidal neovascularization using integrin-mediated sterically stabilized liposomes loaded with combretastatin A4. J Ocul Pharmacol Ther. 2009;25(3): 195-200.

19. Wang Z, Ho PC. A nanocapsular combinatorial sequential drug delivery system for antiangiogenesis and anticancer activities. Biomaterials. 2010;31(27):7115-7123.

20. Wang Z, Ho PC. Self-assembled core-shell vascular-targeted nanocapsules for temporal antivasculature and anticancer activities. Small. 2010;6(22):2576-2583.

21. Tomalia DA, Frechet JM. Dendrimers and Other Dendritic Polymers. New York, NY: John Wiley and Sons Ltd; 2001.

22. Tomalia DA, Naylor AM, Goddard III WA. Starburst dendrimers: control of size, shape, surface chemistry, topology and flexibility in the conversion of atoms to macroscopic materials. Angew Chem Int Ed. 1990;29:138-175.

23. Patri AK, Majoros IJ, Baker JR. Dendritic polymer macromolecular carriers for drug delivery. Curr Opin Chem Biol. 2002;6(4):466-471.

24. Esfand R, Tomalia DA. Poly(amidoamine) (PAMAM) dendrimers from biomimicry to drug delivery and biomedical applications. Drug Discov Today. 2001;6(8):427-436.

25. Shi X, Lee I, Chen X, et al. Influence of dendrimer surface charge on the bioactivity of 2-methoxyestradiol complexed with dendrimers. Soft Matter. 2010;6(11):2539-2545.

26. Wang Y, Cao X, Guo R, et al. Targeted delivery of doxorubicin into cancer cells using a folic acid-dendrimer conjugate. Polym Chem. 2011;2:1754-1760.
27. Wang Y, Guo R, Cao X, Shen M, Shi X. Encapsulation of 2-methoxyestradiol within multifunctional poly (amidoamine) dendrimers for targeted cancer therapy. Biomaterials. 2011;32:3322-3329.

28. Agarwal A, Gupta U, Asthana A, Jain NK. Dextran conjugated dendritic nanoconstructs as potential vectors for anti-cancer agent. Biomaterials. 2009;30:3588-3596.

29. Chandra S, Dietrich S, Lang H, Bahadur D. Dendrimer-Doxorubicin conjugate for enhanced therapeutic effects for cancer. J Mater Chem. 2011;21:5729-5737.

30. Guillaudeu SJ, Fox ME, Haidar YM, Dy EE, Szoka FC, Fréchet JM. PEGylated dendrimers with core functionality for biological applications. Bioconjugate Chem. 2008;19(2):461-469.

31. Majoros IJ, Thomas TP, Mehta CB, Baker JR Jr. Poly (amidoamine) dendrimer-based multifunctional engineered nanodevice for cancer therapy. J Med Chem. 2005;48(19):5892-5899.

32. Majoros IJ, Myc A, Thomas T, Mehta CB, Baker JR Jr. PAMAM dendrimer-based multifunctional conjugate for cancer therapy: synthesis, characterization, and functionality. Biomacromolecules. 2006;7(2):572-579.

33. Baker JR Jr, Quintana A, Piehler L, Banazak-Holl M, Tomalia D, Raczka E. The synthesis and testing of anti-cancer therapeutic nanodevices. Biomed Microdevices. 2001;3(1):61-69.

34. Kukowska-Latallo JF, Candido KA, Cao ZY, et al. Nanoparticle targeting of anticancer drug improves therapeutic response in animal model of human epithelial cancer. Cancer Res. 2005;65(12):5317-5324.

35. Thomas TP, Majoros IJ, Kotlyar A, et al. Targeting and inhibition of cell growth by an engineered dendritic nanodevice. J Med Chem. 2005;48(11):3729-3735.

36. Shi X, Wang SH, Lee I, Shen M, Baker JR Jr. Comparison of the internalization of targeted dendrimers and dendrimer-entrapped gold nanoparticles into cancer cells. Biopolymers. 2009;91(11):936-942.

37. Shi X, Wang SH, Swanson SD, et al. Dendrimer-functionalized shellcrosslinked iron oxide nanoparticles for in-vivo magnetic resonance imaging of tumors. Adv Mater. 2008;20(9):1671-1678.

38. Papadopoulos S, Jürgens KD, Gros G. Protein diffusion in living skeletal muscle fibers: dependence on protein size, fiber type, and contraction. Biophys J. 2000;79:2084-2094.

39. Peer D, Karp JM, Hong S, FarokHzad OC, Margalit R, Langer R. Nanocarriers as an emerging platform for cancer therapy. Nat Nanotechnol. 2007;2:751-760.

40. Shi X, Wang S, Meshinchi S, et al. Dendrimer-entrapped gold nanoparticles as a platform for cancer-cell targeting and imaging. Small. 2007;3:1245-1252.

41. Wang SH, Shi XY, Van Antwerp M, et al. Dendrimer-functionalized iron oxide nanoparticles for specific targeting and imaging of cancer cells. Adv Funct Mater. 2007;17(16):3043-3050.

42. Hong S, Leroueil PR, Majoros IJ, Orr BG, Baker JR Jr, Banaszak Holl MM. The binding avidity of a nanoparticle-based multivalent targeted drug delivery platform. Chem Biol. 2007;14:107-115.

43. Cakara D, Kleimann J, Borkovec M. Microscopic protonation equilibria of poly (amidoamine) dendrimers from macroscopic titrations. Macromolecules. 2003;36(11):4201-4207.

44. Garinchesa P, Campbell I, Saigo PE, Lewis JL, Old LJ, Rettig WJ. Trophoblast and ovarian cancer antigen LK26. Sensitivity and specificity in immunopathology and molecular identification as a folate-binding protein. Am J Pathol. 1993;142(2):557-567. 


\section{Supplementary figures}
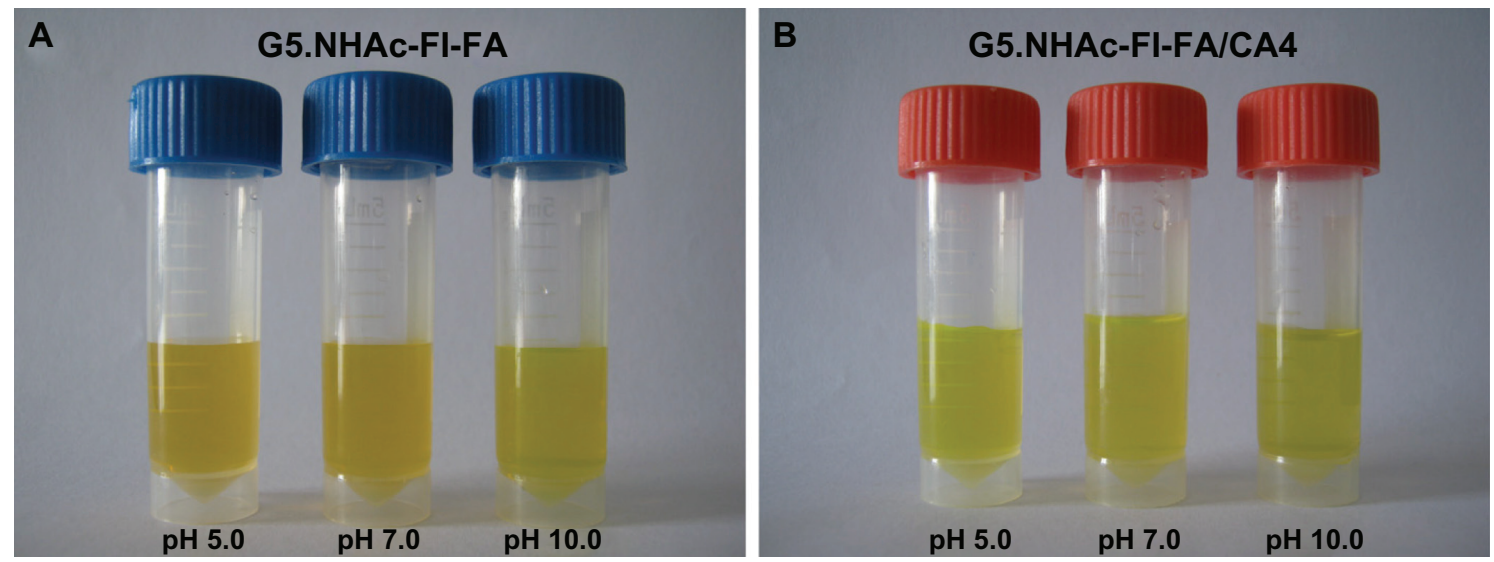

Figure SI The photograph of G5.NHAc-FI-FA dendrimers (A) and G5.NHAc-FI-FA/CA4 complexes (B) dispersed in water at pH values of 5.0, 7.0, and I0.0. Abbreviations: G5, generation 5; G5.NHAc-FI-FA, fluorescein isothiocyanate-modified and folic acid-modified G5 PAMAM dendrimers with acetyl terminal groups; CA4, combretastatin A4.

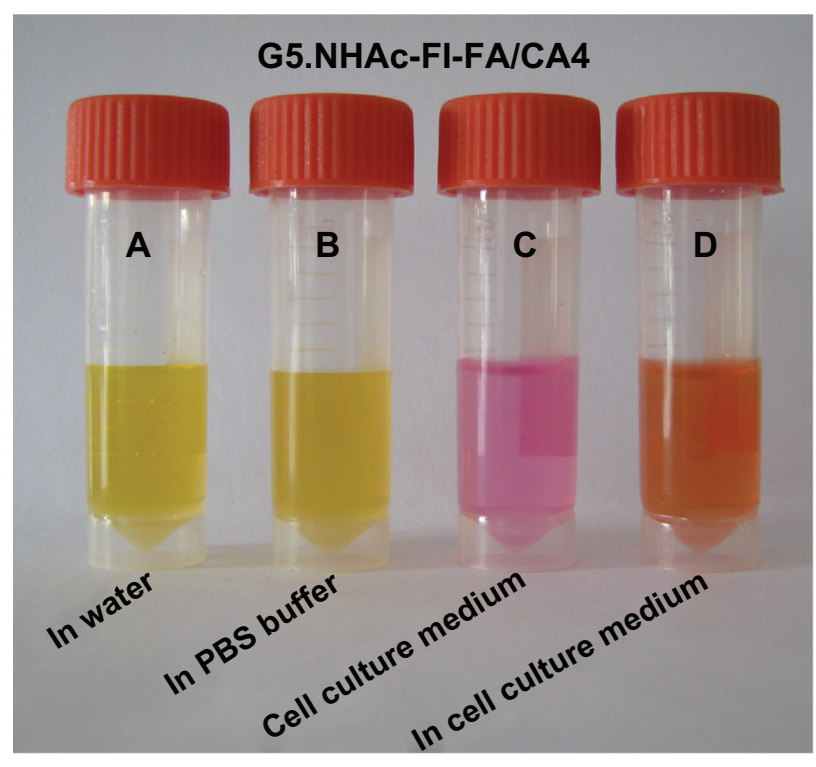

Figure S2 G5.NHAc-FI-FA/CA4 complexes dispersed in (A) water, (B) phosphatebuffered saline, and (D) cell culture medium. (C) Cell culture medium without complexes.

Abbreviations: G5, generation 5; G5.NHAc-FI-FA, fluorescein isothiocyanatemodified and folic acid-modified G5 PAMAM dendrimers with acetyl terminal groups; CA4, combretastatin A4.

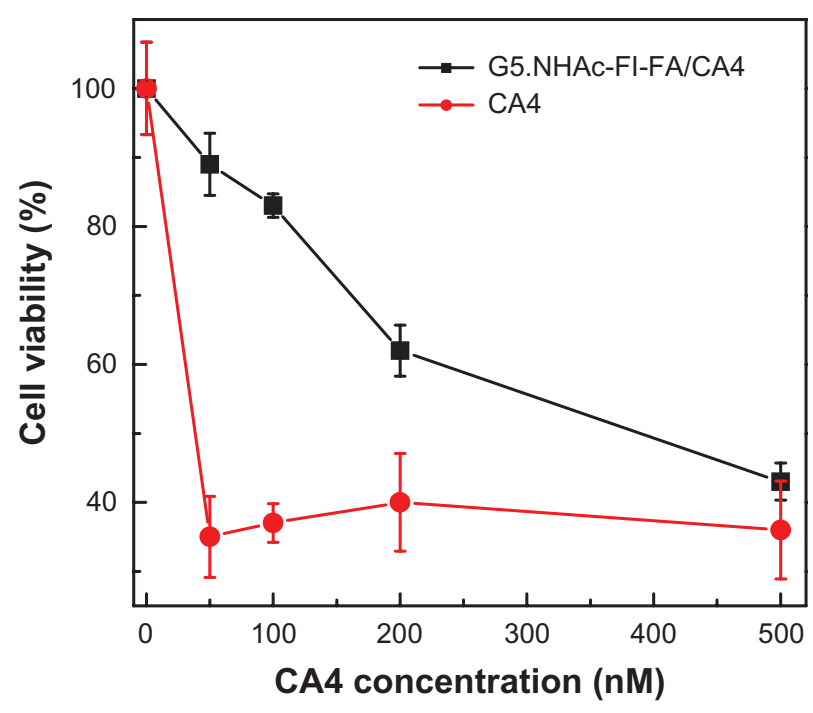

Figure S3 Dose-dependent viability of $K B$ cells treated with free CA4 and G5.NHAc-FI-FA/CA4 complexes.

Abbreviations: G5, generation 5; G5.NHAc-FI-FA, fluorescein isothiocyanatemodified and folic acid-modified G5 PAMAM dendrimers with acetyl terminal groups; CA4, combretastatin A4. 

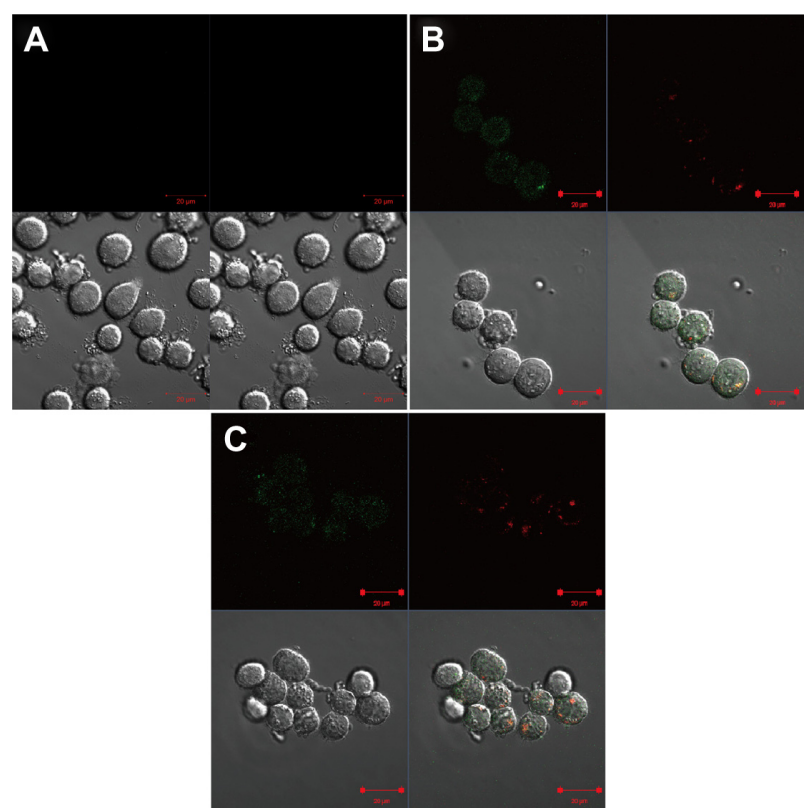

Figure $\mathbf{4} 4$ Confocal microscopic analysis of distribution of G5.NHAc-FI-FA/CA4 complexes into KB-HFAR cells. The cells were incubated with (A) phosphate-buffered saline for one hour, (B) G5.NHAc-Fl-FA/CA4 complexes for one hour, and (C) G5.NHAc-FI-FA/CA4 complexes for 2 hours, respectively. In (B) and (C), cells were treated with Lyso Tracker Red (50 nM) for an additional one hour after treatment with G5.NHAc-FI-FA/CA4 complexes. The upper left of each panel shows the green fluorescence of fluorescein isothiocyanate, the upper right of each panel shows the red fluorescence of Lyso Tracker Red, the lower left of each panel shows the differential interference contrast images, and the lower right of each panel shows merged images with the above three modes.

Abbreviations: G5, generation 5; G5.NHAc-Fl-FA, fluorescein isothiocyanate-modified and folic acid-modified G5 PAMAM dendrimers with acetyl terminal groups; CA4, combretastatin A4.

International Journal of Nanomedicine

\section{Publish your work in this journal}

The International Journal of Nanomedicine is an international, peerreviewed journal focusing on the application of nanotechnology in diagnostics, therapeutics, and drug delivery systems throughou the biomedical field. This journal is indexed on PubMed Central, MedLine, CAS, SciSearch ${ }^{\circledR}$, Current Contents ${ }^{\circledR} /$ Clinical Medicine,
Journal Citation Reports/Science Edition, EMBase, Scopus and the Elsevier Bibliographic databases. The manuscript management system is completely online and includes a very quick and fair peer-review system, which is all easy to use. Visit http://www.dovepress.com/ testimonials.php to read real quotes from published authors.

\footnotetext{
Submit your manuscript here: http://www.dovepress.com/international-journal-of-nanomedicine-journal
} 